\title{
Analysis on Marketing Strategies and Consumer Behavior during Online Shopping Carnival in China
}

\author{
Yuchun $\mathrm{Wu}^{*}$ \\ Central University of Finance and Economics, Beijing 102206, China \\ *Corresponding author: Yuchun Wu, wuyuchun1127@163.com
}

\begin{abstract}
As online shopping carnivals held by giant e-commerce platforms have achieved huge commercial success in terms of both, profit scales and brand building, the marketing strategies that the companies have adopted to promote their ideas and so swiftly influence consumer behavior have attracted wide attention. This article will first begin with the introduction on the phenomenon of online shopping carnival in China especially, the largest one which is the "Double Eleven" Global Online Shopping Carnival where there will be a brief discussion on its nature, history, scale, and huge influence on the Chinese society. Then, the discussion will be focused on the marketing secrets of its contagiousness and the reasons why everyone talks about it from three dimensions whereby it provides social currency, it is of practical value, and it evokes emotions. An analysis will then be done on the marketing contributors to its high sales volume of "Why people are participating?" with purchase motivation theory, social influence theory (SIT), and conformity theory. Finally, the passage will explore the definition of impulse buying as well as its impacting factors in online shopping experiences, and then explain the high incidence of this phenomenon during carnivals from two dimensions which include the low-price strategy and the stimulation from shopping environment. This article aims to help people understand online shopping and shopping carnivals better while the tips of promotion strategies and analysis on consumer behavior would provide a referential value for companies that are interested to raise certain brands' publicity in addition to attract more consumers.
\end{abstract}

Keywords: Online shopping carnival; Social currency; Purchase motivation; SIT, Conformity theory

Publication date: August 2021; Online publication: August 30, 2021

\section{Introduction}

With the development of e-commerce platforms and the popularity of intelligent terminals, the shopping pattern of consumers have greatly changed where online shopping has become extremely common, and there are already 533 million online shoppers existing in China as reported. Nowadays, as the competition between different e-commerce platforms is getting tougher, in order to promote the volume of business and gain fame, some platforms have hosted large-scale online shopping promotional activities associated with special events where this strategy unexpectedly worked out. Among all of them, the most outstanding one is the "Double Eleven" Shopping Carnival, which was originally set up by Tmall on Singles Day, 11th November 2009. After developing for over a decade, in 2020, the overall sales volume of the $11^{\text {th }}$-day carnival reached 840.3 billion yuan (RMB). Also, 69,584 brands from luxury to fast-moving consumer goods (FMCG) and 22 platforms have participated in this battle. Apart from that, related topics on social media have received over 10 billion page views ${ }^{[1]}$. It seems that the "Double Eleven" Global Online Shopping Carnival (GOSC) has aroused national attention in which everyone talks about it, and it nurtured consumers to accustom themselves to go on a shopping spree on this special event. What is worth the 
whistle is that despite the astonishing sales volume, the return rate after the carnival, which was nearly $30 \%$ last year, is also higher than normal from which one can assume that many consumers make impulse purchases during this carnival. The goal of this article is to discuss consumers' behavior during this carnival (everyone talks about the carnival, they spend money on it, and even make impulse purchases), and to analyze the hidden marketing strategies that make them behave in these ways.

\section{Why do people talk about it?}

The first step to succeed in a national shopping carnival is to make people interested. In order to gain fame and arouse people's curiosity, the carnival has adopted various promotion strategies which combine different channels. As Jonah Berger has claimed, "Some things are more contagious than others" and "Regardless of how plain or boring a product or idea may seem, there are ways to make it contagious [2]." The marketing department of this carnival must have done something right to achieve such great word-ofmouth. Berger has summarized six principles that if an idea or product happens to have, it is more likely to be talked about or shared which means it is "contagious." The six principles include social currency, triggers, emotion, public, practical value, and stories. In this section, the six principles will be used to explain the word-of-mouth that the carnival has earned.

\subsection{Social currency}

Social currency implies that what a person talks about influences how others think of that person, which means that if an idea or product could make people look cooler or smarter, people would tend to talk about it. Many platforms have promoted using corresponding strategies. For example, Tmall has made good use of its huge impact in the film and television industry by producing a variety show that invites celebrities and popular stars to share their insights and choices in applying makeup. Another e-commerce platform, JD also performs well. It has organized a talk show which is the most popular and contagious comedy nowadays while using the carnival as its main theme. Hence, when the show is shared with others for social currency, one would naturally mention JD's carnival activities.

\subsection{Practical value}

Practical value implies that people are likely to a share content which has practical value and use it to help others because the feeling of being helpful makes them feel good. The message that is brought on by shopping carnivals naturally has practical value where it helps people to save money with the sales promotion activity. E-commerce platforms have come up with some marketing strategies which make the deals seem to provide more benefit than they actually do. For example, they use the reference point strategy in which people do not evaluate things in absolute terms but evaluate them relative to a standard of comparison by placing the original price of the product next to the discounted price in a very striking way. They have also adopted the restricting availability strategy whereby making promotions more restrictive can actually make them more effective. They would set the promotion only for a limited time and the quantity of the discounted product is also restricted which makes the deal during the carnival seems more valuable as not everyone is accessible to it.

\subsection{Emotion}

"When we feel, then we share." People often like to talk about things that evoke their true feelings. Many brands that cooperate with e-commerce platforms during this carnival are adept with this strategy. Brands like Loreal and Winona have schemed advertising films that focus on topics such as "holding your own heart" and "fighting against gender discrimination" which evoke wide resonance among the young 
generation. In feeling affected by the recognition and sharing the anger about all the inequalities, through these processes, people instinctively talk about certain brands and their promotional activities in the carnival.

\section{Why do people make purchases?}

All behaviors are manipulated and controlled by one's own inner instinct. From the traditional consumer psychology, it is understood that an individual's purchase motivation is what leads that individual to pay. When it comes to shopping carnivals, things have changed. For one, the online shopping experience is quite different from that in physical stores where it is more efficient, convenient, and even the way one would search and experience a certain product are also distinct. Another, the number of participations in the carnival is pretty high, and consumers can easily feel the shopping atmosphere. As a result, one cannot simply conclude that the reason why people are consuming is due to personal purchase motivation, but one should take into consideration of other consumers' impact. This section will analyze why people make purchases from three perspectives which are purchase motivation, social influence theory, and conformity theory.

\subsection{Purchase motivation}

Purchase motivation is the demands and desires one have during shopping which directly impulses the purchase. From former research, purchase motivation can be divided into two categories which are utilitarian and hedonism buyers where the former are buyers who shop for efficiency and quality while the latter includes buyers that shop for experience and pleasure ${ }^{[3]}$. When it comes to the carnival, utilitarian buyers focus on lower prices, shopping convenience, time-saving process, and multiple choices provided by it whereas for hedonism buyers, they value the fancy experience that the carnival brings such as livestreaming shows, visually entertaining designed website and promotion films, themed evening parties, etc.

\subsection{Social influence theory}

SIT implies that the reason why an individual would change his or her behavior is that there are impacting factors in the surrounding social environment including other people's expectations ${ }^{[4]}$. If a person realizes these kinds of impacting factors, he or she would either show a state of false submission or a sincere identification. Bearden believes that when applied to consumers, SIT means that in order to improve one's self-image, meet the expectations of others, or gain enough information on a product or service, consumers tend to change their shopping patterns ${ }^{[5]}$. During shopping carnivals, consumers' shopping inclination is easily affected by other people's shopping intention, preferences, and choices like their fellows, colleagues, families, online celebrities that they follow, and even their online friends. As a result, when they realize that these people are participating actively in this carnival, they may open their e-commerce application and pick out something for themselves in order to make contact or to look trendy and sociable.

\subsection{Conformity theory}

In conformity theory, it is understood that individuals tend to change their behavior or attitude due to group pressure. In the online shopping process, consumers need to deal with tons of information and products where they will tend to search for other people's shopping choices to make better decisions. Group's purchase patterns may in turn set the community rules for individuals. In addition, e-commerce platforms and brands utilize all media channels to promote; relevant advertisements or activities can be seen everywhere both, online as well as offline, and everyone seems to purchase many things during the carnival which causes huge group pressure. It is hard for one to keep calm and spend money rationally under this situation because people may not be happy about being behind the times and missing advantages. 


\section{Why do people make impulsive purchases?}

Impulse buying describes unplanned and irrational purchase behavior that is motivated by triggers such as the product, promotion advertisement, and the environment of the shop. In impulse buying, consumers often experience strong emotional reactions and make decisions without careful considerations. Win and Scholtz have stated that impulse buying is more common with online shopping ${ }^{[6]}$, and from the rate of return that peaks right after the "Double Eleven" GOSC, it is impossible to deny the fact that impulse buying is far from rare during online shopping carnivals.

In earlier research, Dholakia discovered four factors that would trigger impulse buying which are stimulation from external environment, price, individual personality, and purchase situation ${ }^{[7]}$. This section will analyze impulse buying that happens during carnivals from two factors which are price and external environment.

\subsection{Price stimulation}

Piron has pointed out that discounts and promotions are the causes of impulse buying, and when more money is saved, more irrational purchases occur ${ }^{[8]}$. In shopping carnivals, e-commerce platforms cooperate with brands to offer all sorts of discount promotions such as direct price cuts, cashbacks, give-away coupons, random red packets, etc. Hence, for consumers, it is easy to access attractive discounts. Although one may not like certain products or services, the discounts and the money they help to save make them seem like good deals.

\subsection{External environment stimulation}

From Baker's Classification Framework of Shopping Environment Stimulation, there are three stimulations in a shopping environment which include design, atmosphere, and social factor ${ }^{[9]}$. The design factor refers to the decorations and layouts of the e-commerce platforms such as how they present the products, the page instructions, slogans, embellishments, etc. The atmosphere factor is how the shopping platforms use music, artificial intelligence (AI) technologies, videos, games, and activities to provide high-quality auditory and visual experiences with a sense of entertainment. Social factor is the stimulation that occurs when consumers interact with others such as online communication, reputation, the number of transactions, and customer service. During a carnival, which is the biggest promotion activity of all e-commerce platforms, engineers have designed the platforms so elaborately that it is easy to notice the discounts and most desirable products in addition to being convenient to access the products or categories that the consumers are interested in. In terms of the shopping atmosphere, themed evening shows with the hottest stars, crowds of promotion videos and songs produced by brands, specialized live streaming over months, etc. create a kind of atmosphere that one cannot deny. Although one may not be touched by the discounts, one can hardly resist all the novel and interesting thoughts. During the carnival period, e-commerce shops would hire numerous temporary online customer servers to provide high-grade service for each customer in case the consumer load is too large. In addition, majority of the discounted products are either the classic, popular ones or the new arrivals in which they all make consumers feel respected and awake their shopping desires. With the combined effect of the sweet design, enjoyable atmosphere, and humanized service, it is unavoidable for consumers to escape this attractive trap without paying through the nose.

\section{Disclosure statement}

The author declares that there is no conflict of interest. 


\section{References}

[1] 2020, Report on E-commerce Industry During "Double Eleven" Global Online Shopping Carnival, Aurora Mobile.

[2] Berger J, 2013, Contagious: Why Things Catch On, Simon \& Schuster.

[3] Babin BJ, Darden WR, Griffin M, 1994, Work and/or fun: Measuring Hedonic and Utilitarian Shopping Value. Journal of Consumer Research, vol.20, no.4, 1994, pp. 644-656.

[4] Xiao X, Wang T, et al., 2017, Research on the Continuance of Social Media from a Social Influence Theory Perspective. Journal of Management Sciences in China, 20(11): 49-69.

[5] Bearden WO, Netemeyer R G, Teel JE, 1989, Measurement of Consumer Susceptibility to Interpersonal Influence. Journal of Consumer Research, 15(4): 473-84.

[6] Win MZ, Scholtiz RZ, 1998, Impulse Radio: How It Works. IEEE Communications Letter, 2(4): 36-8.

[7] Daholakia UM, 2000, Temptation and Resilience: An Integrated Model of Consumption Impulse Formation and Enact. Psychology and Marketing, 17(11): 955-82.

[8] Piron F, 1991, Defining Impulse Purchasing. Advances in Consumer Research, 18(1): 509-14.

[9] Baker J, Parasuraman A, Gruwal D, et al., 2002, The Influence of Multiple Store Environment Cues on Perceived Merchandise Value and Patronage Intentions. Journal of Marketing, 66(2): 120-41. 